\title{
Global Sea Level Acceleration
}

\author{
Bruce C. Douglas \\ National Oceanographic Data Center, NOAA, Washington, D. C.
}

\begin{abstract}
Greenhouse warming scenarios commonly forecast an acceleration of sea level rise in the next 5 or $6+$ decades in the range $0.1-0.2 \mathrm{~mm} / \mathrm{yr}^{2}$. Long tide gauge records ( 75 years minimum) have been examined for past apparent sea level acceleration (i.e., deviation from a purely linear rise) and for indication of how long it might take to detect or verify a predicted future acceleration. For the 80-year period 1905-1985, 23 essentially complete tide gauge records in 10 geographic groups are available for analysis. These yielded the apparent global acceleration $-0.011( \pm 0.012) \mathrm{mm} / \mathrm{yr}^{2}$. A larger, less uniform set of 37 records in the same 10 groups with 92 years average length covering the 141 years from 1850 to 1991 gave for acceleration $0.001( \pm 0.008) \mathrm{mm} / \mathrm{yr}^{2}$. Thus there is no evidence for an apparent acceleration in the past $100+$ years that is significant either statistically, or in comparison to values associated with global warming. Estimating how well a global acceleration parameter could be determined in a relatively short time was accomplished by dividing the 1905-1985 data set into four equal time spans. The formal $1 \sigma$ uncertainty (about $0.2 \mathrm{~mm} / \mathrm{yr}^{2}$ ) of global acceleration from these 20-year periods is more than an order of magnitude larger than for the 80- and 141-year cases owing to the existence of large interdecadal and longer variations of sea level. This means that tide gauges alone cannot serve as a leading indicator of climate change in less than at least several decades. Confirming the prediction of a particular model at the $95 \%$ confidence level or differentiating between model predictions will take much longer. The time required can be significantly reduced if the interdecadal fluctuations of sea level can be understood in terms of their forcing mechanisms and then removed from the tide gauge records.
\end{abstract}

\section{INTRODUCTION}

Global sea level rise is the subject of an extensive literature; excellent summary analyses are available in Sea Level Change [National Research Council (NRC), 1990] and the Intergovernmental Panel on Climate Change (IPCC) report Climate Change [Houghton et al., 1990]. Interest in sea level rise is high because of its obvious practical impact and its scientific value as a parameter of global change. In the latter respect, global sea level is similar to Earth orientation [Carter et al., 1989]. Both give measures that are necessary (but not sufficient) conditions for evaluating model predictions.

The IPCC report gives for the "business-as-usual" scenario of global warming an additional sea level change of 18 $\mathrm{cm}$ by 2030 and $44 \mathrm{~cm}$ by 2070 , corresponding to accelerations of about $0.22 \mathrm{~mm} / \mathrm{yr}^{2}$ in the former case and 0.14 $\mathrm{mm} / \mathrm{yr}^{2}$ for the latter. Verification of these or similar predictions at an early date is necessary in order to establish confidence in climate models and forecasts.

Woodworth [1990] has investigated past apparent sea level acceleration and observes that the large number of tide gauges in the Baltic-Northern European region, although subject to linear vertical movements from glacial rebound, provides data suitable for study of the nonlinear component of sea level change. However, in his study he did not exploit the regional spatial correlation of the sea level signal at low frequencies, which has the effect of overemphasizing the importance of the very large number of tide gauges in northern Europe. We shall see below that a compact oceanic region containing records of varying lengths should be modeled by a linear trend for each tide gauge record along with a single acceleration parameter that simultaneously satisfies (in the sense of least squares) all records.

This paper is not subject to U.S. copyright. Published in 1992 by the American Geophysical Union.

Paper number 92JC01133.
Woodworth [1990] also considered existing long records outside of Europe and concluded that there is little or no evidence for a statistically significant apparent acceleration of sea level in them. In addition, he attempted to show by an extrapolation of (meteorologically corrected) historic sea level residual data from the Newlyn, England, site that the acceleration in a region might be detected in about 3 decades, subject to certain assumptions concerning sea level variability. The present paper is less optimistic, taking note of the ubiquity of large chaotic regional sea level events that endure over a decade or more. These events can distort an estimate of regional sea level acceleration over even very long records and are devastating to records of a few decades' duration.

Before proceeding further, it is necessary to clarify what is meant in this paper, as well as in others such as Woodworth's [1990], by the term acceleration. This usage refers to the deviation of sea level from a linear trend over the data span in question that is modeled by an algebraic term of the second degree in time. It is necessary to explicitly state this because the true spectrum of sea level is red. This has the consequence that any particular span of sea level data, such as the period 1850 to present considered in this paper, will represent as an acceleration to a lesser or greater extent those low-frequency changes of sea level whose periods are significant in comparison to, or longer than, the data span. Thus the accelerations derived and referred to in this paper are really apparent ones, whose significance lies only in their amplitude relative to the acceleration predicted to accompany global warming.

Determinations of sea level acceleration suffer the same problems affecting determinations of the linear sea level rise value [Douglas, 1991], with an important exception, namely, vertical crustal movements. The most prevalent of these is postglacial rebound. This effect [Peltier and Tushingham, 1989] is linear over the time span for which tide gauge data are available and is of no consequence in computation of the 


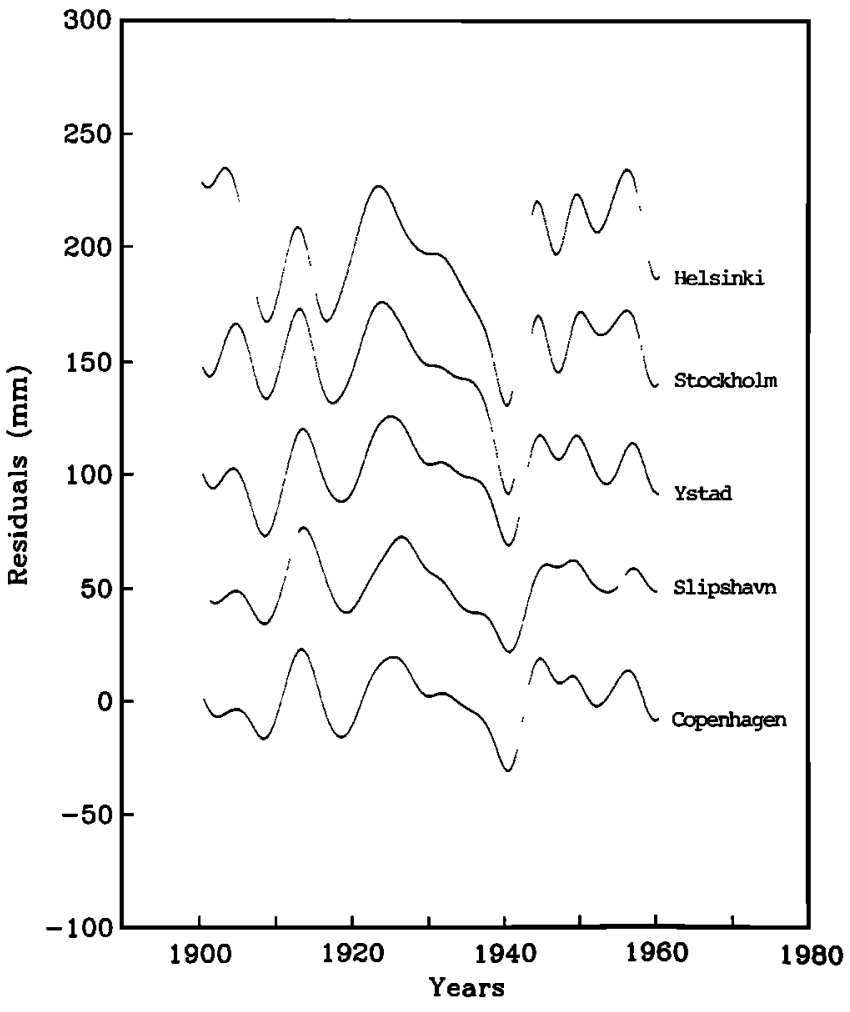

Fig. 1. Detrended and low-pass-filtered sea level records in the Baltic. Note the extraordinary coherence at low frequency.

acceleration in a record. Any other temporally linear vertical crustal movement, such as that associated with colliding tectonic plates at places with long earthquake recurrence times, is similarly not a factor. The result is that many more tide gauge records are useable for an analysis of apparent global sea level acceleration than in the case of the linear trend.

Although more gauges are available for analysis of apparent sea level acceleration than for the case of the linear rise, this is of little significance. The reason is that at low frequency, spatial coherence of sea level is very great. Thus a region such as the Baltic, although containing a score of long records, is effectively more like a single measurement system for interdecadal to centennial and longer sea level variations. Figure 1 illustrates this phenomenon. The data are monthly mean values of sea level from the Permanent Service for Mean Sea Level (PSMSL) [Spencer and Woodworth, 1991] that have been detrended over the common time period 1895-1965, and smoothed by a Gaussian filter with full width at half maximum (FWHM) of 4 years. Five typical sea level records in ascending order from the southernmost part of the Baltic northward to Stockholm and then well eastward into the Gulf of Finland are displayed. The temporal coherence of the records over decades is striking. This low-frequency "noise" corrupts a determination of acceleration from these records and is clearly not independent from one site to another. In addition, the records are obviously serially correlated in time at low frequencies, so that the standard deviation obtained for an acceleration parameter from an ordinary least squares fit to the data will be very optimistic. Such large and persistent oscillatory sea level events, present in most tide gauge time series, radically affect the value of apparent sea level acceleration derived from even very long records. How these events can affect a determination of sea level acceleration is shown in Figure 2. Presented are the filtered and detrended sea level records for Nedre Sodertalje and Stockholm, sites only about $25 \mathrm{~km}$ apart and with records nearly the same length at just over 90 years. The difference between them is that Nedre Sodertalje covers an earlier period reaching back into the 1860 s during which another large persistent sea level event, verified by other old records, took place. Using the original unfiltered monthly mean sea level (MSL) values for Stockholm and Nedre Sodertalje in a least squares fit to the function

$$
\text { MSL }=(S A)+(A)+a+b t+1 / 2 c t^{2}
$$

(where $S A$ and $A$ are semiannual and annual periodic terms) yields values of -0.01 and $-0.03 \mathrm{~mm} / \mathrm{yr}^{2}$, respectively, for the acceleration $c$. Although both give small values for acceleration, the earlier sea level event causes the acceleration derived from the Nedre Sodertalje sea level series to be 3 times that obtained from the Stockholm record. The difference in values is not negligible; if it were real, it would amount to $10 \mathrm{~cm}$ in 100 years. This shows that the sea level acceleration derived for a site depends on the data span in question for even 100-year records and that the uncertainty of a result is dominated by the low-frequency sea level variations. Determining a meaningful global value requires using a well-distributed set of oceanic regions that lack interregional coherence. For this paper, 10 regions were selected on a morphological basis by examining the regional sea level records. The average length of the records selected

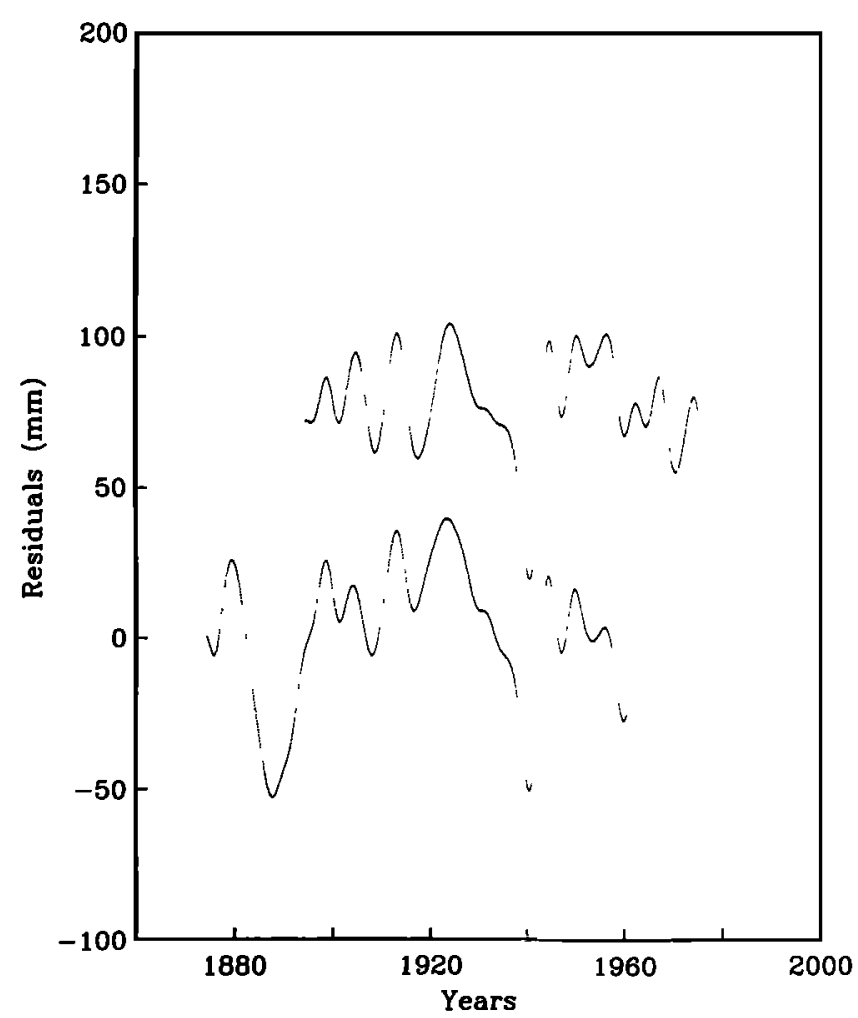

Fig. 2. Low-pass-filtered and detrended records for (top) Stockholm and (bottom) Nedre Sodertalje. Both records are more than 90 years in length but do not yield the same apparent sea level acceleration because of the somewhat different periods sampled. 
is 92 years, covering the period 1850-1991. In addition, a time period (1905-1985) was found during which all records are essentially complete and all regions contain at least one station. Choosing data sets this latter way eliminates the problems associated with the presence or absence of persistent large sea level events in groups containing records of unequal length.

\section{Regional and Global Apparent Sea level ACCELERATION}

In the previous paper by Douglas [1991] on global sea level rise, the condition was enforced that all records used had to be about $80 \%$ or more complete because of the presence of low-frequency sea level variations. From the comments above, it is clear that the apparent acceleration determined for a site can also be affected by a data gap, so the same condition was applied for this analysis.

As we have seen, record length is a critical parameter in selection of data sets. Figure 3 shows how record length affects the apparent acceleration estimate by displaying it as a function of data span for PSMSL records $>10$ years long. The scatter of accelerations for records less than about $\mathbf{4 0}$ years is very great; the reason for the striking increase in consistency beginning with records $>50$ years is unknown. Of course the scatter of shorter records in Figure 3 is due to absorption of interdecadal variability into the acceleration parameter estimate. The figure clearly shows the site dependence of apparent sea level acceleration for records even many decades in length.

Although the disparity of values in Figure 3 is discouraging, it is worth pointing out that the number of values with short records available is very large, since many new gauges have been installed in recent decades. The oceanic regions selected in this paper with records $>75$ years in length do not represent what is possible for the recent past or near future. But as can be seen in the example of the Baltic, a new tide gauge is really only significant for the sea level trend and acceleration problem if it is located in a new area not previously sampled. Even allowing for some argument as to what constitutes an oceanic region, it is unlikely that their number could be doubled from the number (10) chosen for this paper. Since a doubling of independent samples only reduces the error of the mean by $40 \%$, the importance of understanding and eliminating interdecadal and longer lowfrequency variations of sea level is underscored.

Table 1 presents the groups of stations used for an analysis of apparent sea level acceleration during the period approximately 1850-1990. The largest group is the one covering the North Sea at Esbjerg on into the Baltic entrance and thence to the Gulf of Finland. Four of the groups contain only one station. We shall see below that the disparity of numbers of stations between groups is far less important than might be supposed.

If Table 1 is compared with the list of stations used by Douglas [1991] it will be seen that other new stations are used in this paper in addition to those in the Baltic. In the previous work, Bombay, Tonoura, and Seattle were rejected on the basis of vertical crustal movements, and Sydney was eliminated because of differences with a nearby site over an extended interval. The situation in the present investigation for Seattle is straightforward. Comparison of detrended records for Seattle and nearby gauges over a common time

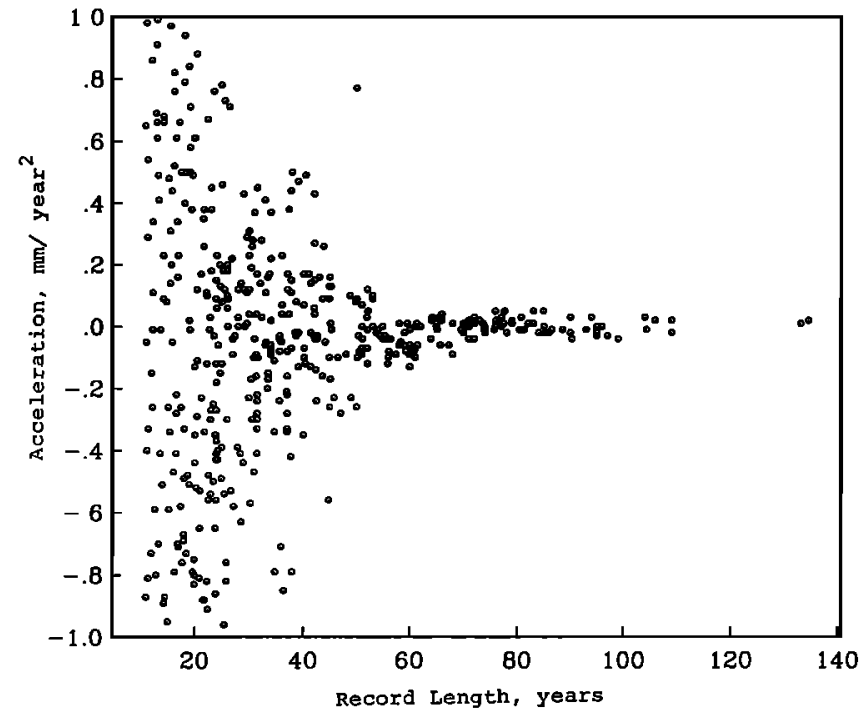

Fig. 3. Apparent accelerations of sea level for records $>10$ years in length. Low-frequency variations of sea level heavily corrupt the computation of an acceleration parameter for records less than about 50 years in length.

period shows a very high degree of consistency at low frequencies, indicating that the longer Seattle record is representative of the entire region as far as nonlinear changes are concerned.

The situation is more ambiguous for Bombay because very large differences in sea level variation exist for Indian gauges over any common time interval. But Bombay is not the site of frequent earthquakes, so vertical crustal movements should be absorbed into the linear trend value. The remaining site, Tonoura, was added to the list because after detrending, the record shows no obvious breaks that might have resulted from a large earthquake.

The remaining new sites used in this paper are Auckland, New Zealand; Sydney, Australia; and Buenos Aires, Argentina. The first has been reported on by Hannah [1990], who kindly made available the monthly mean values for use in this paper. The detrended Auckland record closely resembles that of Sydney at low frequencies, so the two are considered to be in a single region and the quality of the Sydney record is verified. Buenos Aires was previously unavailable.

Acceleration parameters for each record are shown in Table 1 in the last column. There is some scatter, but the majority of values are far less in absolute value than the predicted future acceleration of sea level rise of about 0.2 $\mathrm{mm} / \mathrm{yr}^{2}$. It is also worth noting that the 37 values are evenly distributed as to sign. Table 1 suggests that the apparent acceleration of sea level in the last $100+$ years has been small but cannot identify the sign.

The apparent acceleration of sea level for individual groups in Table 1 was estimated according to the following scheme. For each group, a unique trend for every station and an acceleration satisfying all stations were estimated simultaneously. Thus records of disparate length in a group are correctly weighted, and the records that reach very far back will influence the calculated value of acceleration for the group. The group accelerations are given in Table 2. Note that they are also evenly divided as to sign. 
TABLE 1. Stations With Records Exceeding 75 Years During 1850-1991

\begin{tabular}{|c|c|c|c|c|c|c|}
\hline & Latitude & Longitude & Start & End & $\begin{array}{l}\text { Span, } \\
\text { years }\end{array}$ & $\begin{array}{c}\text { Acceleration, } \\
\mathrm{mm} / \mathrm{yr}^{2}\end{array}$ \\
\hline \multicolumn{7}{|c|}{ Group I } \\
\hline Goteborg & $57^{\circ} 43^{\prime} \mathrm{N}$ & $11^{\circ} 57^{\prime} \mathrm{E}$ & 1887 & 1969 & 82 & 0.01 \\
\hline Varberg & $57^{\circ} 06^{\prime} \mathrm{N}$ & $12^{\circ} 13^{\prime} \mathrm{E}$ & 1887 & 1982 & 95 & -0.03 \\
\hline Ystad & $55^{\circ} 25^{\prime} \mathrm{N}$ & $13^{\circ} 49^{\prime} \mathrm{E}$ & 1887 & 1982 & 95 & -0.03 \\
\hline Kungholmsfort & $56^{\circ} 06^{\prime} \mathrm{N}$ & $15^{\circ} 35^{\prime} \mathrm{E}$ & 1887 & 1982 & 95 & 0.00 \\
\hline Landsort & $58^{\circ} 45^{\prime} \mathrm{N}$ & $17^{\circ} 52^{\prime} \mathrm{E}$ & 1887 & 1982 & 95 & -0.02 \\
\hline Nedre Sodertalje & $59^{\circ} 12^{\prime} \mathrm{N}$ & $17^{\circ} 37^{\prime} \mathrm{E}$ & 1869 & 1966 & 97 & -0.03 \\
\hline Stockholm & $59^{\circ} 19^{\prime} \mathrm{N}$ & $18^{\circ} 05^{\prime} \mathrm{E}$ & 1889 & 1982 & 93 & -0.01 \\
\hline Bjorn & $60^{\circ} 38^{\prime} \mathrm{N}$ & $17^{\circ} 58^{\prime} \mathrm{E}$ & 1892 & 1970 & 85 & 0.00 \\
\hline Ratan & $64^{\circ} 00^{\prime} \mathrm{N}$ & $20^{\circ} 55^{\prime} \mathrm{E}$ & 1892 & 1982 & 90 & -0.02 \\
\hline Oulu/Uleaborg & $65^{\circ} 02^{\prime} \mathrm{N}$ & $25^{\circ} 25^{\prime} \mathrm{E}$ & 1889 & 1988 & 99 & -0.04 \\
\hline Vaasa/Vasa & $63^{\circ} 06^{\prime} \mathrm{N}$ & $21^{\circ} 34^{\prime} \mathrm{E}$ & 1883 & 1988 & 104 & -0.01 \\
\hline Lyokki & $60^{\circ} 51^{\prime} \mathrm{N}$ & $21^{\circ} 11^{\prime} \mathrm{E}$ & 1858 & 1937 & 79 & 0.02 \\
\hline Lypyrtti & $60^{\circ} 36^{\prime} \mathrm{N}$ & $21^{\circ} 14^{\prime} \mathrm{E}$ & 1858 & 1937 & 79 & 0.01 \\
\hline Helsinki & $60^{\circ} 09^{\prime} \mathrm{N}$ & $24^{\circ} 58^{\prime} \mathrm{E}$ & 1879 & 1988 & 109 & 0.02 \\
\hline Kobenhavn & $55^{\circ} 41^{\prime} \mathrm{N}$ & $12^{\circ} 36^{\prime} \mathrm{E}$ & 1889 & 1970 & 81 & -0.01 \\
\hline Fredericia & $55^{\circ} 34^{\prime} \mathrm{N}$ & $9^{\circ} 46^{\prime} \mathrm{E}$ & 1889 & 1970 & 80 & -0.01 \\
\hline Aarhus & $56^{\circ} 09^{\prime} \mathrm{N}$ & $10^{\circ} 13^{\prime} \mathrm{E}$ & 1888 & 1969 & 81 & -0.01 \\
\hline Esbjerg & $55^{\circ} 28^{\prime} \mathrm{N}$ & $8^{\circ} 27^{\prime} \mathrm{E}$ & 1889 & 1970 & 81 & -0.01 \\
\hline \multicolumn{7}{|c|}{ Group 2} \\
\hline Aberdeen II & $57^{\circ} 09^{\prime} \mathrm{N}$ & $2^{\circ} 05^{\prime} \mathrm{W}$ & 1862 & 1966 & 104 & 0.03 \\
\hline North Shields & $55^{\circ} 00^{\prime} \mathrm{N}$ & $1^{\circ} 27^{\prime} \mathrm{W}$ & 1895 & 1991 & 96 & 0.00 \\
\hline Newlyn & $50^{\circ} 06^{\prime} \mathrm{N}$ & $5^{\circ} 33^{\prime} \mathrm{W}$ & 1915 & 1991 & 76 & -0.01 \\
\hline Brest & $48^{\circ} 23^{\prime} \mathrm{N}$ & $4^{\circ} 30^{\prime} \mathrm{W}$ & 1807 & 1991 & 184 & 0.01 \\
\hline Cascais & $38^{\circ} 41^{\prime} \mathrm{N}$ & $9^{\circ} 25^{\prime} \mathrm{W}$ & 1882 & 1987 & 106 & 0.02 \\
\hline \multicolumn{7}{|c|}{ Group 3} \\
\hline Marseille & $43^{\circ} 18^{\prime} \mathrm{N}$ & $5^{\circ} 21^{\prime} \mathrm{E}$ & 1885 & 1988 & 103 & -0.02 \\
\hline Genoa & $44^{\circ} 24^{\prime} \mathrm{N}$ & $8^{\circ} 54^{\prime} \mathrm{E}$ & 1884 & 1989 & 105 & 0.00 \\
\hline Trieste & $45^{\circ} 39^{\prime} \mathrm{N}$ & $13^{\circ} 45^{\prime} \mathrm{E}$ & 1905 & 1991 & 86 & -0.02 \\
\hline \multicolumn{7}{|c|}{ Group 4} \\
\hline Bombay & $18^{\circ} 55^{\prime} \mathrm{N}$ & $72^{\circ} 50^{\prime} \mathrm{E}$ & 1878 & 1987 & 109 & -0.02 \\
\hline \multicolumn{7}{|c|}{ Group 5} \\
\hline Tonoura & $34^{\circ} 54^{\prime} \mathrm{N}$ & $132^{\circ} 04^{\prime} \mathrm{E}$ & 1894 & 1984 & 90 & -0.04 \\
\hline \multicolumn{7}{|c|}{ Group 6} \\
\hline Sydney & $33^{\circ} 51^{\prime} \mathrm{S}$ & $151^{\circ} 14^{\prime} \mathrm{E}$ & 1897 & 1991 & 94 & 0.03 \\
\hline Auckland & $36^{\circ} 51^{\prime} \mathrm{S}$ & $174^{\circ} 46^{\prime} \mathrm{E}$ & 1904 & 1989 & 85 & -0.02 \\
\hline \multicolumn{7}{|c|}{ Group 7} \\
\hline Honolulu & $21^{\circ} 19^{\prime} \mathrm{N}$ & $157^{\circ} 52^{\prime} \mathrm{W}$ & 1905 & 1989 & 84 & -0.02 \\
\hline \multicolumn{7}{|c|}{ Group 8} \\
\hline Seattle & $47^{\circ} 36^{\prime} \mathrm{N}$ & $122^{\circ} 20^{\prime} \mathrm{W}$ & 1899 & 1989 & 90 & 0.03 \\
\hline San Francisco & $37^{\circ} 48^{\prime} \mathrm{N}$ & $122^{\circ} 28^{\prime} \mathrm{W}$ & 1854 & 1989 & 134 & 0.02 \\
\hline San Diego & $32^{\circ} 43^{\prime} \mathrm{N}$ & $117^{\circ} 10^{\prime} W$ & 1906 & 1989 & 83 & 0.01 \\
\hline \multicolumn{7}{|c|}{ Group 9} \\
\hline Buenos Aires & $34^{\circ} 36^{\prime} \mathrm{S}$ & $58^{\circ} 22^{\prime} \mathrm{W}$ & 1905 & 1988 & 83 & 0.05 \\
\hline \multicolumn{7}{|c|}{ Group 10} \\
\hline Baltimore & $39^{\circ} 16^{\prime} \mathrm{N}$ & $76^{\circ} 35^{\prime} \mathrm{W}$ & 1902 & 1989 & 86 & -0.01 \\
\hline New York & $40^{\circ} 42^{\prime} \mathrm{N}$ & $74^{\circ} 01^{\prime} \mathrm{W}$ & 1856 & 1989 & 133 & 0.01 \\
\hline
\end{tabular}

The average record length is $\mathbf{9 2}$ years. Apparent accelerations are for the entire records.

The standard deviations shown in Table 2 for the individual group acceleration parameters are based on an estimate of the noise level of the data and have been adjusted to give an a posteriori variance of unit weight of 1 . Of course the larger groups give more precise results because of the huge number of values in them. But not too much should be made of these formal uncertainties because they are based on the usual least squares assumption that the data noise is Gaussian and independent between sea level series in each group, assumptions clearly unwarranted for estimates of acceleration. Thus the mean acceleration of the groups shown in Table 2 was calculated giving each group estimate equal weight. These 10 groups should give a more meaningful estimate of mean global apparent sea level acceleration and its uncertainty because their individual estimates are a more statistically independent sample than the member stations in a region. The $1 \sigma$ error of the mean shown in Table 2 is based on the residuals about that mean, and for this case of 10 samples the $95 \%$ confidence interval is 2.26 times larger. From Table 2 we conclude that at the $95 \%$ confidence level the mean apparent acceleration across all groups is less than $10 \%$ of the acceleration anticipated in global warming scenarios for the future.

The largest apparent accelerations in Table 2 are for Tonoura, Japan, and Buenos Aires, Argentina. Tonoura has a relatively smooth record that is concave downward [Dou- 
TABLE 2. Apparent Acceleration Values for the Groups Shown in Table 1

\begin{tabular}{ccc}
\hline Group & Acceleration, $\mathrm{mm} / \mathrm{yr}^{2}$ & St. Dev. \\
\hline 1 & -0.010 & 0.002 \\
2 & 0.011 & 0.003 \\
3 & -0.008 & 0.005 \\
4 & -0.015 & 0.006 \\
5 & -0.039 & 0.010 \\
6 & 0.015 & 0.007 \\
7 & -0.016 & 0.012 \\
8 & 0.022 & 0.003 \\
9 & 0.046 & 0.012 \\
10 & 0.006 & 0.003 \\
\hline
\end{tabular}

Mean acceleration $=0.001 \mathrm{~mm} / \mathrm{yr}^{2}( \pm 0.008)$. The error of the mean was computed from the residuals about the mean, not from the errors of the individual estimates.

glas, 1991], giving a large negative apparent acceleration. Buenos Aires, in contrast, shows periodic large interdecadal events lacking in the Tonoura record. What it might yield for acceleration after the record is extended a few decades may be very different. We see that while long sea level records free of vertical crustal movements or for which a postglacial rebound model [e.g., Peltier and Tushingham, 1989] is available give very close to the same trend [Douglas, 1991], accelerations are a different matter. The real acceleration, if any, in existing long records is too small compared with low-frequency undulations in the data.

It is possible to find a long ( 80 years) period in which each of the 10 groups in Table 1 has at least one member. Table 3 presents these 10 groups, with some surprising omissions of well known and widely used records. Notably absent are Brest, Marseille, and Genoa. Figures 4 and 5 show the reason for their deletion from the 1905-1985 analysis.

Figure 4 shows detrended and filtered records for Brest and Newlyn, which are near (about $150 \mathrm{~km}$ ) to each other. The agreement is very good until 1939 , at which time they diverge. Subsequently, a gap begins in the Brest record, and just after the gap ends, the two series once again agree. Apparently, prior to the beginning of the data gap, the Brest gauge malfunctioned. In comparing data records of nearby gauges, it is not unusual for data gaps to be preceded or

TABLE 3. Stations With Nearly Complete Records From 1905-1985

\begin{tabular}{|c|c|c|c|c|}
\hline & Latitude & Longitude & $\begin{array}{c}\text { Acceleration, } \\
\mathrm{mm} / \mathrm{yr}^{2}\end{array}$ & $\begin{array}{c}\text { Group } \\
\text { Acceleration }\end{array}$ \\
\hline \multicolumn{5}{|c|}{ Group I } \\
\hline Varberg & $57^{\circ} 06^{\prime} \mathrm{N}$ & $12^{\circ} 13^{\prime} \mathrm{E}$ & -0.028 & \\
\hline Ystad & $55^{\circ} 25^{\prime} \mathrm{N}$ & $13^{\circ} 49^{\prime} \mathrm{E}$ & -0.017 & \\
\hline Kungholmsfort & $56^{\circ} 06^{\prime} \mathrm{N}$ & $15^{\circ} 35^{\prime} \mathrm{E}$ & 0.031 & \\
\hline Landsort & $58^{\circ} 45^{\prime} \mathrm{N}$ & $17^{\circ} 52^{\prime} \mathrm{E}$ & 0.009 & \\
\hline Stockholm & $59^{\circ} 19^{\prime} \mathrm{N}$ & $18^{\circ} 05^{\prime} \mathrm{E}$ & -0.001 & \\
\hline Ratan & $64^{\circ} 00^{\prime} \mathrm{N}$ & $20^{\circ} 55^{\prime} \mathrm{E}$ & -0.019 & \\
\hline Oulu/Uleaborg & $65^{\circ} 02^{\prime} \mathrm{N}$ & $25^{\circ} 25^{\prime} \mathrm{E}$ & -0.006 & \\
\hline Vaasa/Vasa & $63^{\circ} 06^{\prime} \mathrm{N}$ & $21^{\circ} 34^{\prime} \mathrm{E}$ & -0.008 & \\
\hline Helsinki & $60^{\circ} 09^{\prime} \mathrm{N}$ & $24^{\circ} 58^{\prime} \mathrm{E}$ & 0.034 & 0.000 \\
\hline \multicolumn{5}{|c|}{ Group 2} \\
\hline Cascais & $38^{\circ} 41^{\prime} \mathrm{N}$ & $9^{\circ} 25^{\prime} \mathrm{W}$ & -0.021 & -0.024 \\
\hline \multicolumn{5}{|c|}{ Group 3} \\
\hline \multicolumn{5}{|c|}{ Group 4} \\
\hline \multicolumn{5}{|c|}{ Group 5} \\
\hline Tonoura & $34^{\circ} 54^{\prime} \mathrm{N}$ & $132^{\circ} 04^{\prime} \mathrm{E}$ & -0.064 & -0.064 \\
\hline \multicolumn{5}{|c|}{ Group 6} \\
\hline Sydney & $33^{\circ} 51^{\prime} \mathrm{S}$ & $151^{\circ} 14^{\prime} \mathrm{E}$ & 0.047 & \\
\hline Auckland & $36^{\circ} 51^{\prime} \mathrm{S}$ & $174^{\circ} 46^{\prime} \mathrm{E}$ & -0.009 & 0.019 \\
\hline \multicolumn{5}{|c|}{ Group 7} \\
\hline Honolulu & $21^{\circ} 19^{\prime} \mathrm{N}$ & $157^{\circ} 52^{\prime} \mathrm{W}$ & -0.013 & -0.013 \\
\hline \multicolumn{5}{|c|}{ Group 8} \\
\hline Seattle & $47^{\circ} 36^{\prime} \mathrm{N}$ & $122^{\circ} 20^{\prime} \mathrm{W}$ & 0.044 & \\
\hline San Francisco & $37^{\circ} 48^{\prime} \mathrm{N}$ & $122^{\circ} 28^{\prime} \mathrm{W}$ & 0.029 & \\
\hline San Diego & $32^{\circ} 43^{\prime} \mathrm{N}$ & $117^{\circ} 10^{\prime} \mathrm{W}$ & 0.019 & 0.031 \\
\hline \multicolumn{5}{|c|}{ Group 9} \\
\hline \multirow{2}{*}{\multicolumn{5}{|c|}{$\begin{array}{l}\text { Group I0 } \\
76^{\circ} 35^{\prime} \mathrm{W}\end{array}$}} \\
\hline Baltimore & $39^{\circ} 16^{\prime} \mathrm{N}$ & $76^{\circ} 35^{\prime} W$ & -0.011 & \\
\hline New York & $40^{\circ} 42^{\prime} \mathrm{N}$ & $74^{\circ} 01^{\prime} \mathrm{W}$ & -0.015 & -0.013 \\
\hline
\end{tabular}

The formal uncertainty of each record is about the same at about $0.015 \mathrm{~mm} / \mathrm{yr}^{2}$. The mean apparent acceleration of the groups is $-0.011( \pm 0.012) \mathrm{mm} / \mathrm{yr}^{2}$, with the uncertainty calculated from the scatter about the mean. 


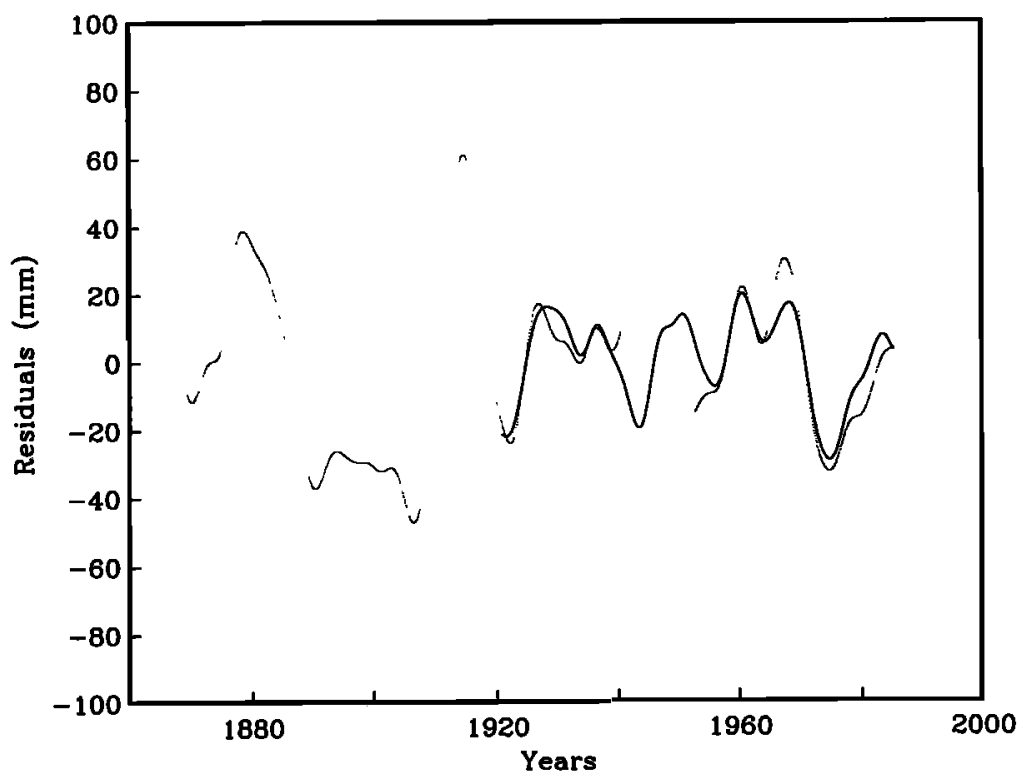

Fig. 4. Detrended and filtered sea level records for Brest (dots) and Newlyn (solid line). Note the departure of the records in 1939 just prior to the gap.

followed by deviant sea level values. For this paper, Brest data were eliminated from 1939 until 1958. This results in a long gap in the Brest record, too long for an analysis of the 1905-1985 time period.

The situation for Marseille during 1905-1985 is presented in Figure 5. As shown, the Marseille sea level record deviates sharply from Trieste (about $500 \mathrm{~km}$ distant) beginning in about 1945, suffers a data gap, and then reappears in good agreement after about 1970 . In contrast, Trieste agrees well with Genoa during this time (and over all of the time they have in common) in spite of being on opposite sides of the Italian peninsula. It was concluded that the Marseille record is faulty during 1945-1958, and so the entire series was eliminated because of the large gap. Genoa was also eliminated because it covers only a limited portion of the period 1905-1985.

The acceleration parameter estimates for the period 19051985 are shown in the last column of Table 3. Both the mean value and the uncertainty are larger than in the case of the longer records, and once again, it can only be concluded that the deviation from a linear rise is small compared with the acceleration predicted to accompany global warming.

Figure 3 suggests that a record as short as 50 years should give a small uncertainty for acceleration. This is verified by computing a solution for the apparent mean acceleration of the 10 groups in Table 3 from 1935 to 1985 . The result is $0.003( \pm 0.03) \mathrm{mm} / \mathrm{yr}^{2}$. Shorter spans are less encouraging. The result of subdividing the consistent set of records

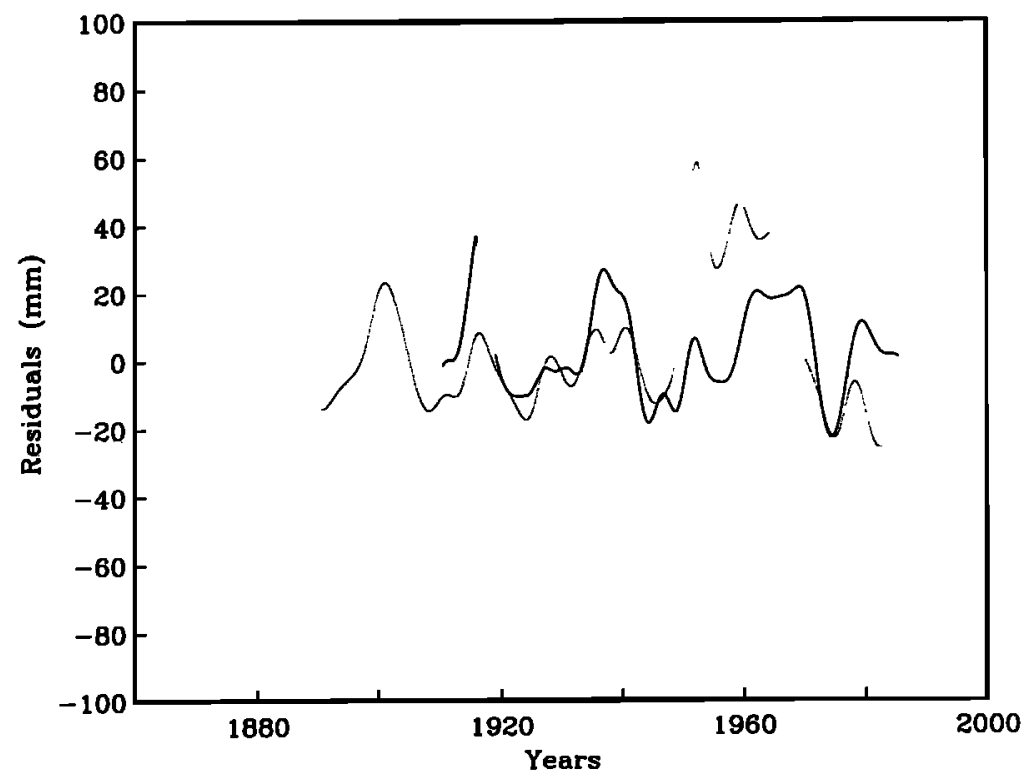

Fig. 5. Detrended and filtered sea level for Marseille (dots) and Trieste (solid line). The records agree well until about 1945, at which time Marseille deviates sharply from Trieste. The latter agrees well with Genoa during this time, indicating a problem with the Marseille record. 
TABLE 4. Apparent Accelerations and Errors for the 80-Year Period 1905-1985 Subdivided Into Four Groups

\begin{tabular}{ccc}
\hline Interval & Acceleration, $\mathrm{mm} / \mathrm{yr}^{2}$ & $\begin{array}{c}\text { Standard } \\
\text { Deviation }\end{array}$ \\
\hline $1905-1925$ & -0.219 & 0.18 \\
$1925-1945$ & -0.129 & 0.20 \\
$1945-1965$ & -0.162 & 0.15 \\
$1965-1985$ & +0.265 & 0.20 \\
\hline
\end{tabular}

Note that the standard deviations are an order of magnitude larger than the value for the entire 80 -year period and are comparable to the acceleration expected in the future.

constituting the 1905-1985 data set into four 20-year subsets and determining the global acceleration parameter for each is shown in Table 4. What we see is what Figure 3 suggests; the $1 \sigma$ uncertainty of apparent global sea level acceleration determined from 20-year records is more than an order of magnitude greater than for 50- to 80-year series and is comparable to the acceleration of sea level anticipated by climate models.

\section{Discussion}

This paper has considered the apparent acceleration of sea level in 10 regions and used an estimation scheme for each region that determines simultaneously a trend for each station in the region and an acceleration parameter for the entire region. This procedure should give a more optimal estimate of apparent acceleration in an area with records of disparate length. The conclusion reached is, however, the same as that of Woodworth [1990] in his more straightforward analysis of European records. He also concluded that there is no evidence of an acceleration effect in sea level in the historical record that is in any way comparable to that associated with most global warming predictions for the future.

An issue as interesting as the apparent past acceleration of sea level is whether or not sea level can be used as a "leading indicator" of climate change either regionally or globally. Since an acceleration of $0.2 \mathrm{~mm} / \mathrm{yr}^{2}$ amounts to only $1 \mathrm{~cm}$ in 10 years and $4 \mathrm{~cm}$ in 20 years, the outlook for tide gauge measurements by themselves is clearly not good. These values are small compared with the interannual-interdecadal variations of sea level, casting doubt that a useful index of sea level acceleration can be obtained relatively quickly. This observation is entirely consistent with Figure 3 and the results given in Table 4 for the uncertainty of global accelerations derived from 20 -year records. As noted previously, for records less than a few decades, the acceleration parameter absorbs the low-frequency variations of sea level and gives a fictitious result.

Woodworth [1990] also emphasizes the importance of the interannual-interdecadal variability of sea level on attempts at calculating sea level acceleration. However, he goes on to construct a simulated Newlyn sea level record consisting of the past linear trend there and that part of the historic Newlyn sea level series unexplained by meteorological forcing, plus an extrapolated portion into the future that includes a posited acceleration. He then concludes from an analysis of 60 years of these simulated Newlyn data up to 2010 that evidence of an acceleration of the magnitude expected to accompany global warming should be detected at the $95 \%$ confidence level by that time. However, in his Figure 2, which displays the simulated sea level series for Newlyn, one notes that the projected series touches the historic trend line in about 2010 due to the residual interdecadal signal, casting some doubt on the robustness of his conclusion. Fortunately, as Woodworth [1990] points out and is clearly obvious in his Figure 2, by 2020 the acceleration should be readily detected in his scenario using only the previous 30 or so years of data. By 2020 the acceleration in his simulation has caused an accumulated change of sea level that deviates markedly from the historic linear trend.

Although the Newlyn simulation gives an encouraging result for the potential of tide gauges to detect regional sea level acceleration, as Woodworth [1990] explains, the validity of the simulation procedure depends critically on the assumption that the future unmodeled interannualinterdecadal signal will be like that of the past. The low-passfiltered Newlyn record is remarkably stationary in appearance over the data span compared to many tide gauge records, but that span is not indicative of what has actually occurred there. Figure 4, comparing Newlyn and Brest sea level series, shows that a large unpredictable sea level event, that is, a large rise and fall lasting a decade or more, occurred just before the Newlyn series began. (This event is verified by the North Shields record). If this event happened again, it could be mistaken for the beginning of an enduring acceleration of sea level, or at the least would have a corrupting influence on the derived acceleration of sea level. These interdecadal, as opposed to interannual, events are not unusual in any region (consider the Baltic records in Figure 1), nor do they have a simple explanation in terms of meteorological forcing; steric effects are also involved and in general will be far larger in magnitude than meteorological ones at very low frequencies. Because of these events, it will be necessary to consider as many ocean regions as possible, as was done in this paper, and attempt to extract any underlying new trend or acceleration.

It is interesting to consider what can be gained from a few decades of Newlyn sea level values by analyzing actual (i.e., uncorrected for meteorological forcing) Newlyn data from $1950-1982$. The result for the acceleration is $-0.002( \pm 0.12)$ $\mathrm{mm} / \mathrm{yr}^{2}$. The $95 \%$ confidence interval is thus about 0.24 , a little larger than the value $\left(0.2 \mathrm{~mm} / \mathrm{yr}^{2}\right)$ anticipated for the acceleration that may result from global warming. Such a result clearly demonstrates the absolute necessity of understanding the source of the low-frequency variations of sea level in tide gauge records. The Newlyn data show that an acceleration at a site cannot be determined to a degree useful for evaluating regional climate model forecasts in even 3 decades from sea level records whose low frequency variations are not well understood.

\section{Conclusions}

Consideration of a global set of tide gauge records made since $\mathbf{1 8 5 0}$ leads to the conclusion that the apparent acceleration of sea level since that time has been small and much less than the real acceleration predicted to accompany greenhouse warming. However, confidently determining the future value of global sea level acceleration from tide gauge data alone would appear to require something approaching 50 years, according to the results quoted earlier for a 50 year global solution, and by inference from Figure 3. But this is 
too pessimistic for a final conclusion about using sea level as an indicator of global warming. Since the problem lies in the large interannual-interdecadal variations of sea level, these must be measured or modeled and removed from the data. This has been accomplished for one site, Bermuda, for a few decades. Roemmich $[N R C, 1990]$ shows that the $O(10 \mathrm{~cm})$ interdecadal variations of sea level there are explained by the density changes above $2000 \mathrm{~m}$ depth to within the accuracy of the measurements. It seems clear that a relatively small number of island and properly selected coastal tide gauges well distributed around the globe, at which the effects of meteorological forcing and the ocean's (perhaps complex) response are thoroughly understood, might give a reliable estimate of sea level acceleration in a much shorter time than tide gauge data alone.

Finally, satellite altimetry offers a new method for observing low-frequency variations of sea level. Even though the accuracy of point values of sea level variation from satellite data is lower than that of tide gauges, the global coverage given by satellites has the potential of yielding a very precise value of global sea level. Cheney et al. [1991] have obtained agreement of $3-4 \mathrm{~cm}$ (rms) with individual island tide gauges for Geosat monthly mean values of sea level. Miller and Cheney [1990] have shown that much better regional results are possible. They obtained 9-mm (rms) agreement between the average of 14 tropical Pacific gauges and the average of corresponding Geosat sea level series. A coordinated effort consisting of tide gauge measurements, altimetric satellites, meteorological data, water column density observations, and modeling should enable an acceleration of sea level to be observed soon enough to be of value in evaluating climate models and forecasts.

Acknowledgments. I wish to thank Ed Herbrechtsmeir for making the computations for this paper. This investigation was carried out under the auspices of the NOAA Climate and Global Change program directed by the NOAA Office of Global Programs.

\section{REFERENCES}

Carter, W. E., et al., Geodetic fixing of tide gauge bench marks, 44 pp., Tech. Rep. WHOI-89-31, Woods Hole Oceanogr. Inst., Woods Hole, Mass., Aug., 1989.

Cheney, R. E., W. J. Emery, B. J. Haines, and F. Wentz, Recent improvements in Geosat altimeter data, Eos Trans. $A G U, 72(51)$, 577-580, 1991.

Douglas, B. C., Global sea level rise, J. Geophys. Res., 96(C4), 6981-6992, 1991.

Hannah, J., Analysis of mean sea level data from New Zealand for the period 1899-1988, J. Geophys. Res., 95(B8), 12,399-12,405, 1990.

Houghton, J. T., G. J. Jenkins, and J. J. Ephraums (Eds.), Climate Change, pp. 261-285, Cambridge University Press, New York, 1990.

Miller, L., and R. E. Cheney, Large-scale meridional transport in the tropical Pacific Ocean during the 1986-1987 El Niño from Geosat, J. Geophys. Res., 95(C10), 17,905-17,919, 1990.

National Research Council (NRC), Sea Level Change, 234 pp. National Academy Press, Washington, D. C., 1990.

Peltier, W. R., and A. M. Tushingham, Global sea level rise and the greenhouse effect: Might they be connected?, Science, 244(4906), 806-810, 1989.

Spencer, N. E., and P. L. Woodworth, 1991 Data Holdings of the Permanent Service for Mean Sea Level, Permanent Serv. for Mean Sea Level, Bidston, England, Jan. 1991.

Woodworth, P. L., A search for accelerations in records of European mean sea level, Int. J. Climatol., 10, 129-143, 1990.

B. C. Douglas, National Oceanographic Data Center, NOAA, Washington, DC 20235.
(Received February 10, 1992;

revised April 15, 1992;

accepted April 28, 1992.) 